Pacific Journal of Mathematics

ON THE STRICT AND UNIFORM CONVEXITY OF CERTAIN 


\section{ON THE STRICT AND UNIFORM CONVEXITY OF CERTAIN BANACH SPACES}

\section{K. SUNDARESAN}

Let $(X, S, \mu)$ be a $\sigma$-finite non-atomic measure space let $N$ be a real valued continuous convex even function defined on the real line such that

(1) $N(u)$ is nondecreasing for $u \geqq 0$,

(2) $\lim _{u \rightarrow \infty} N(u) / u=\infty$,

(3) $\lim _{u \rightarrow 0} N(u) / u=0$.

Let $L_{N}$ be the set of all real valued $\mu$-measurable functions $f$ such that $\int_{\boldsymbol{X}} N(f) d \mu<\infty$. It is known that if there exists a constant $k$ such that $N(2 u) \leqq k N(u)$ for all $u \geqq 0$ then $L_{N}$ is a linear space; in fact, $\mathrm{L}_{N}$ is a $B$-Space if a norm $\|\cdot\|$ is defined by setting

$$
\|f\|=\inf \left\{1 / \zeta \mid \zeta>0, \int_{X} N(\eta, f) d \mu \leqq 1\right\} .
$$

Denoting the $B$-space $\left(L_{N},\|\cdot\|\right)$ by $L_{N}^{*}$ it is proposed to obtain the necessary and sufficient conditions in order that $L_{N}^{*}$ may be (1) Strictly Convex (2) Uniformly Convex.

The linear space $L_{N}$ admits another norm $\|\cdot\|_{(N)}$ known as the Orlicz norm defined by setting

$$
\left\|\left|f \|_{(N)}=\sup \int_{x}\right| f g \mid d \mu\right.
$$

for such that $\int_{x} M(|g|) d \rho \leqq 1, M$ being the function complementary to $N$ in the sense of Young. For a discussion of this class of Banach spaces we refer to Mazur and Orlicz [2]. Convexity properties of the Orlicz norm have been studied in Milnes [3].

The space $L_{N}^{*}$ may be considered as a modulared linear space defined in Nakano [4]. A nonnegative extended real valued function $m$ defined on a linear space is called a modular if

(i) $m(0)=0$;

(ii) for any $x \in L$ there exists $\xi>0$ such that $m(\xi x)<\infty$;

(iii) $m(\xi x)=0$ for all $\xi>0$ implies $x=0$;

(iv) $m(x)=\sup _{0 \leqq \xi<1} m(\xi x)$;

(v) $m$ is convex (i.e., $\alpha \geqq 0, \beta \geqq 0, \alpha+\beta=1, x, y \in L$ imply $m(\alpha x+\beta y) \leqq \alpha m(x)+\beta m(y))$.

Received January 20, 1965. Research work supported by N.S.F. Grant GP-378. 
The modulared linear space may be considered as a normed linear space if a norm $\|\cdot\|$ is defined by setting

$$
\|x\|=\inf \{1 / \xi \mid \xi>0 \text { and } m(\xi x) \leqq 1\} \text {. }
$$

We note that the linear space $L_{N}$ is a modulared space if

$$
m(f)=\int_{X} N(f) d \mu,
$$

and the norm $\|\cdot\|$ defined by $(* *)$ is the same as the norm defined in $*$. In fact, the modulared space $L_{N}$ is a finite modulared space, meaning that $m(f)<\infty$, for all $f \varepsilon L_{N}$.

A Banach space $B$ is said to be strictly convex if $x, y \in B,\|x\|=$ $\|y\|=\|(x+y) / 2\|=1$ imply $x=y$. It is uniformly convex if to each $\varepsilon, 0<\varepsilon \leqq 2$, there corresponds a $\delta(\varepsilon)>0$ such that conditions $\|x\|=$ $\|y\|=1,\|x-y\| \geqq \varepsilon$ imply that $\|x+y\|<2-\delta(\varepsilon)$.

We shall start by characterizing the strict convexity of $L_{N}^{*}$.

LemMA 1. The modulared norm defined in (**) associated with a finite modulared space is strictly convex if and only if $m(x)=$ $m(y)=m\{(x+y) / 2)\}=1$ imply $x=y$.

The proof is an easy consequence of the fact that in a finite modulared space, $m(x)=1$ if and only if $\|x\|=1$ where $\|\cdot\|$ is the related modulared norm.

THEOREM. The Banach space $L_{N}^{*}$ is strictly convex if and only if the $N$-function $N$ is strictly convex; i.e.,

$$
N\left(\frac{u+v}{2}\right)<\frac{1}{2}[N(u)+N(v)]
$$

for all real $u, v$ such that $u \neq v$.

Proof. Let $N$ be a strictly convex $N$-function. Let $f, g \in L_{N}^{*}$ such that

$$
m(f)=m(g)=m\left(\frac{f+g}{2}\right)=1 .
$$

By definition of $m$ it follows that

$$
\left.\int_{x}\left[\frac{N(f)+N(g)}{2}\right]-N\left(\frac{f+g}{2}\right)\right] d \ell=0 .
$$

whence the convexity of $N$ together with the restrictions on $f$, and $g$ imply that $f=g$ a.e. Thus by Lemma $1, L_{N}^{*}$ is strictly convex. 
To prove the "only if" part, let $L_{N}^{*}$ be strictly convex. If possible let $N$ be not striclly convex so that there exist $a, b \geqq 0 \quad a \neq b$ such that $N\{(a+b) / 2\} \quad 1 / 2[N(a)+N(b)]$. The continuity of $N$ together with the condition $\lim N(u) / u=0$ imply that $N$ is linear on the interval $[a, b]$ and $a \neq 0, b, 0$. For $u \in[a, b]$ let $N(u)=p u+q$, where $p$ and $q$ are reals.

Since $\mu$ is a nonatomic positive measure there exist pairwise disjoint measurable sets $A, B, C$ of arbitrarily small measure such that

$$
\mu(A)=\mu(B)=\mu(C) \text {. }
$$

Let us define functions $\mathrm{f}, \mathrm{g}$ as follows. Let $f(x)=a$ for $x \in A, f(x)=b$ for $x \in B$, and $f(x)=0$ for all $x \notin A \cup B$. Let $g(x)=b$ for $x \in A$, $g(x)=a$ for $x \in B$, and $g(x)=0$ for $x \notin A \cup B$, and $g(x)=0$ for $x \notin A \cup B$. Then

$$
\begin{aligned}
m(f) & =\int_{X} N(f) d \mu=[p(a+b)+2 q] \mu(A), \\
m(g) & =\int_{X} N(g) d \mu=[p(a+b)+2 q] \mu(B), \\
m\left(\frac{f+g}{2}\right) & =\frac{1}{2}[m(f)+m(g)],
\end{aligned}
$$

and $m(f)=m(g)=m\{(f+g) / 2)\}$. By a suitable choice of $A, B, C$ we can assume that

$$
m(f)=m(g)=m\left(\frac{f+g}{2}\right)=K<\frac{1}{2} .
$$

Now let $h$ be a function on $X$ defined by setting

$$
h(x)=0 \text { if } X \in C, \quad h(x)=t \text { if } x \in C
$$

where $t$ in wuch that $N(t) f_{\ell}(C)=1 \cdots K$. Let $f_{\mathrm{t}}=h+f$, and $g_{1}=$ $h+g ;$ since $h \wedge i \quad 0 \quad h \wedge \ell$, we obtain

$$
m(i) \quad m(h), m(f)=(1-K)+K=1 .
$$

Similarly $m\left(y_{1}\right) \quad$ 1, und further

$$
m\left(\frac{\left.f_{1}+\|\right)}{2}\right) \quad m\left(\begin{array}{c}
f \\
2
\end{array}, h\right)=m\left(\frac{f+g}{2}\right)+m(h)=1 .
$$

Thus we have $f_{1}$, $l_{*}, \boldsymbol{u}_{1} \cdot l_{*}$ und $m\left(f_{1}\right)=m\left(g_{1}\right)=m\left\{\left(f_{1}+g_{1} / 2\right)\right\}=1$; however $f_{1} \neq g_{1}$. 'Thus $l_{\text {, * }}$ is not strictly convex, a contradiction.

We next proced (1) charuclerize the uniform convexity of $L_{N}^{*}$.

It is known [5/ thin in a modulared semiordered linear space, the ? modular norm is uniformly convex if and only if the associated norm 
is uniformly convex. The modulared linear spaces $L_{N}$ are modulared semiordered linear spaces under the natural pointwise ordering, and the above two norms are respectively the norms $\|\cdot\|_{(N)}$ and $\|\cdot\|_{(N)} \cdot$ With this remark we conclude that the Theorem 8 in Milnes [3] which characterizes the uniform convexity of the norm $\|\cdot\| \|_{(N)}$ also characterizes the uniform convexity of the norm $\|\cdot\|_{(N)}$.

I wish to thank Professor Victor L. Klee for his valuable suggestions during the preparation of the manuscript, and the referee for his suggestions and corrections which lead to a revision of the manuscript.

\section{REFERENCES}

1. Krasnoselikii and Rutickii, Convex functions and Orlicz spaces, Translation by L. F. Boron, Nordoff Ltd., 1961.

2. Mazur and Orlicz, On some classes of linear spaces, Stud. Mathem. 17 (1957), 97-119.

3. H. W. Milnes, Convexity in Orlicz spaces, Pacific J. Math. 7 (1957), 1451-1458.

4. H. Nakano, Topology and Linear Topological Spaces, Maruzen and Co., 1951, pp. 204.

5. Ando Tsyuoshi, Convexity and evenness in modulared semi-ordered linear spaces, J. Fac. Sci. Hokkaido Univ. Ser 1.14, (1955), 59-95.

UNIVERSITY OF WASHINGTON

AND

Carnegie Institute of TeChNology 


\section{PACIFIC JOURNAL OF MATHEMATICS}

\section{EDITORS}

\author{
H. Samelson \\ Stanford University \\ Stanford, California \\ R. M. Blumenthal \\ University of Washington \\ Seattle, Washington 98105
}

\author{
J. Dugundu \\ University of Southern California \\ Los Angeles, California 90007 \\ *Richard Arens \\ University of California \\ Los Angeles, California 90024
}

\section{ASSOCIATE EDITORS}
E. F. BeCKENBACH
B. H. NeUMANN
F. WOLF
K. YosidA

\section{SUPPORTING INSTITUTIONS}

\author{
UNIVERSITY OF BRITISH COLUMBIA \\ CALIFORNIA INSTITUTE OF TECHNOLOGY \\ UNIVERSITY OF CALIFORNIA \\ MONTANA STATE UNIVERSITY \\ UNIVERSITY OF NEVADA \\ NEW MEXICO STATE UNIVERSITY \\ OREGON STATE UNIVERSITY \\ UNIVERSITY OF OREGON \\ OSAKA UNIVERSITY \\ UNIVERSITY OF SOUTHERN CALIFORNIA
}

\author{
STANFORD UNIVERSITY \\ UNIVERSITY OF TOKYO \\ UNIVERSITY OF UTAH \\ WASHINGTON STATE UNIVERSITY \\ UNIVERSITY OF WASHINGTON \\ * * * * \\ AMERICAN MATHEMATICAL SOCIETY \\ CALIFORNIA RESEARCH CORPORATION \\ SPACE TECHNOLOGY LABORATORIES \\ NAVAL ORDNANCE TEST STATION
}

Mathematical papers intended for publication in the Pacific Journal of Mathematics should by typewritten (double spaced). The first paragraph or two must be capable of being used separately as a synopsis of the entire paper. It should not contain references to the bibliography. No separate author's resumé is required. Manuscripts may be sent to any one of the four editors. All other communications to the editors should be addressed to the managing editor, Richard Arens, at the University of California, Los Angeles, California 90024.

50 reprints per author of each article are furnished free of charge; additional copies may be obtained at cost in multiples of 50 .

The Pacific Journal of Mathematics is published quarterly, in March, June, September, and December. Effective with Volume 13 the price per volume (4 numbers) is $\$ 18.00$; single issues, $\$ 5.00$. Special price for current issues to individual faculty members of supporting institutions and to individual members of the American Mathematical Society: $\$ 8.00$ per volume; single issues $\$ 2.50$. Back numbers are available.

Subscriptions, orders for back numbers, and changes of address should be sent to Pacific Journal of Mathematics, 103 Highland Boulevard, Berkeley 8, California.

Printed at Kokusai Bunken Insatsusha (International Academic Printing Co., Ltd.), No. 6, 2-chome, Fujimi-cho, Chiyoda-ku, Tokyo, Japan.

PUBLISHED BY PACIFIC JOURNAL OF MATHEMATICS, A NON-PROFIT CORPORATION

The Supporting Institutions listed above contribute to the cost of publication of this Journal, but they are not owners or publishers and have no responsibility for its content or policies.

* Basil Gordon, Acting Managing Editor until February 1, 1966. 


\section{Pacific Journal of Mathematics}

\section{Vol. 15, No. $3 \quad$ November, 1965}

David R. Arterburn and Robert James Whitley, Projections in the space of

bounded linear operators .................................

Robert McCallum Blumenthal, Joram Lindenstrauss and Robert Ralph Phelps,

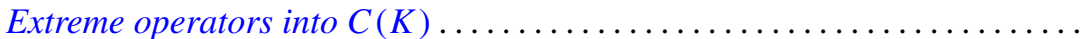

L. Carlitz, A note on multiple exponential sums ................... 757

Joseph A. Cima, A nonnormal Blaschke-quotient .................... 767

Paul Civin and Bertram Yood, Lie and Jordan structures in Banach algebras . . . 775

Luther Elic Claborn, Dedekind domains: Overrings and semi-prime

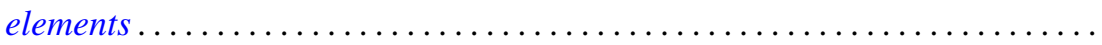

799

Luther Elic Claborn, Note generalizing a result of Samuel's .............. 805

George Bernard Dantzig, E. Eisenberg and Richard Warren Cottle, Symmetric

dual nonlinear programs ................................... 809

Philip J. Davis, Simple quadratures in the complex plane ............... 813

Edward Richard Fadell, On a coincidence theorem of F. B. Fuller ............ 825

Delbert Ray Fulkerson and Oliver Gross, Incidence matrices and interval

graphs ........................................ 835

Larry Charles Grove, Tensor products over $H^{*}$-algebras ..................

Deborah Tepper Haimo, $L^{2}$ expansions in terms of generalized heat polynomials



I. Martin (Irving) Isaacs and Donald Steven Passman, A chardcterization of groups in terms of the degrees of their characters ..........

Donald Gordon James, Integral invariants for vectors over local fields........ 905

Fred Krakowski, A remark on the lemma of Gauss ................... 917

Marvin David Marcus and H. Minc, A subdeterminant inequality ........... 921

Kevin Mor McCrimmon, Norms and noncommutative Jordan algebras ........ 925

Donald Earl Myers, Topologies for Laplace transform spaces ............... 957

Olav Njstad, On some classes of nearly open sets .................... 961

Milton Philip Olson, A characterization of conditional probability ........... 971

Barbara Osofsky, A counter-example to a lemma of Skornjakov .............. 985

Sidney Charles Port, Ratio limit theorems for Markov chains ............... 989

George A. Reid, A generalisation of $W^{*}$-algebras ...................... 1019

Robert Wells Ritchie, Classes of recursive functions based on Ackermann's

function ........................................... 1027

Thomas Lawrence Sherman, Properties of solutions of $n$th order linear

differential equations ........................................ 1045

Ernst Snapper, Inflation and deflation for all dimensions . .............. 1061

Kondagunta Sundaresan, On the strict and uniform convexity of certain Banach

spaces............................................. 1083

Frank J. Wagner, Maximal convex filters in a locally convex space .......... 1087

Joseph Albert Wolf, Translation-invariant function algebras on compact 